\title{
Self-assembled silver nanoparticles monolayers on mica- AFM, SEM, and electrokinetic characteristics
}

\author{
Magdalena Oćwieja • Maria Morga • \\ Zbigniew Adamczyk
}

Received: 28 September 2012/Accepted: 21 January 2013/Published online: 9 February 2013

(C) The Author(s) 2013. This article is published with open access at Springerlink.com

\begin{abstract}
A monodisperse silver particle suspension was produced by a chemical reduction method in an aqueous medium using sodium citrate. The average particle size determined by dynamic light scattering (DLS), transmission electron microscopy (TEM), and atomic force microscopy (AFM) was $28.5 \mathrm{~nm}$. The DLS measurements confirmed that the suspension was stable for the ionic strength up to $3 \times 10^{-2} \mathrm{M} \mathrm{NaCl}$. The electrophoretic mobility measurements revealed that the electrokinetic charge of particles was negative for $\mathrm{pH}$ range $3-10$, assuming $-50 e$ for $\mathrm{pH}=9$ and $0.01 \mathrm{M} \mathrm{NaCl}$. Using the suspension, silver particle monolayers on mica modified by poly(allylamine hydrochloride) were produced under diffusion-controlled transport. Monolayer coverage, quantitatively determined by AFM and SEM, was regulated within broad limits by adjusting the nanoparticle deposition time. This allowed one to uniquely express the zeta potential of silver monolayers, determined by the in situ streaming potential measurements, in terms of particle coverage. Such dependencies obtained for
\end{abstract}

M. Oćwieja $(\bowtie) \cdot$ M. Morga $\cdot$ Z. Adamczyk

Jerzy Haber Institute of Catalysis and Surface Chemistry, Polish Academy of Sciences, Niezapominajek 8, 30-239

Cracow, Poland

e-mail: ncocwiej@cyf-kr.edu.pl

M. Morga

e-mail: ncmorga@cyf-kr.edu.pl

Z. Adamczyk

e-mail: ncadamcz@cyf-kr.edu.pl various ionic strengths and $\mathrm{pH}$, were successfully interpreted in terms of the 3D electrokinetic model. A universal calibrating graph was produced in this way, enabling one to determine silver monolayer coverage from the measured value of the streaming potential. Our experimental data prove that it is feasible to produce uniform and stable silver particle monolayers of well-controlled coverage and defined electrokinetic properties.

Keywords Adsorption - Heterogeneous surfaces . Zeta potential $\cdot$ Streaming potential $\cdot$ Silver monolayers

\section{Introduction}

On the last few years, silver nanoparticle have been extensively studied due to their potential applications in emerging areas of nanoscience and technology. They are widely applied in catalysis (Jiang et al. 2005), microelectronics (Li et al. 2005; Magdassis et al. 2003) or in medicine as antibacterial agents (Kim et al. 2007). Also, due to the efficient surface plasmon resonance, silver particles are used in surfaceenhanced Raman spectroscopy (SERS) (Kaczor et al. 2010) and metal-enhanced fluorescence (MEF) (Aslan et al. 2005).

Silver nanoparticles are also frequently used to modify various organic and inorganic substrates to 
obtain materials of novel properties. However, most of practical applications of silver nanoparticles involve thin films deposited on various solid surfaces. Such films can serve as catalytic materials (Yougen et al. 2012), anti-reflecting layers (Kachan et al. 2006 coatings), antibacterial coatings (Lee et al. 2003), and active substrates for spectroscopy (Lee et al. 1997).

These thin films are usually produced via physical methods such as evaporation, sputtering (Arbab 2001), chemical vapor deposition (CVD) (Yuan et al. 1995), chemical bath deposition (CBD) (Estrada-Raygoza et al. 2006), lithographical techniques (Green and Liu 2003), electroless plating (Kim et al. 2008) and the sonoprocess method (Inoue et al. 2010). However, these techniques are expensive and require sophisticated equipment. Moreover, the purity and stability of silver films obtained in this way, are not satisfactory. Other disadvantages include a poor control of coverage and particle homogeneity within monolayers. To avoid such problems, the colloid self-assembly methods based on diffusion-controlled deposition of silver particles from stable suspensions can be used. This allows one to produced homogeneous, dense, almost defect-free, and ultrathin films (Mittler 2010). In this way, monolayers of controlled coverage and homogeneity can be produced by adjusting the suspension concentration, $\mathrm{pH}$, ionic strength, and the deposition time (Brouwer et al. 2003; Kleimann et al. 2006; Oćwieja et al. 2011, 2012a, b). However, in these works indirect ex situ methods of particle monolayer characteristics such as UV-Vis surface plasmon adsorption (Bar et al. 1996), atomic force microscopy (AFM) (Yang et al. 2007), scanning electron microscopy (SEM), quartz crystal microgravimetry (QCM) (Bandyopadhyay et al. 1997), ellipsometry and reflectometry (Reiter et al. 1992) were used.

Therefore, the main goal of this work is to develop an efficient method for the in situ characterization of silver particle monolayers on solid substrates based on the streaming potential measurements. The method allows one to directly determine the kinetics of particle adsorption and desorption under various transport conditions such as diffusion and forced convection (flow). Thorough electrokinetic characteristics of the monolayers formed in this way can be exploited to determine their stability against $\mathrm{pH}$ cycling and ionic strength variations. This has major significance for optimizing the conditions of stable silver nanoparticle film preparation. It should be mentioned that up to our knowledge no such electrokinetic characteristics of silver particle monolayers on solid substrates have been reported in the literature.

\section{Experimental}

\section{Materials}

All chemical reagents used in the experiments (silver nitrate, trisodium citrate, sodium chloride, sodium hydroxide, and hydrochloric acid) were commercial products of Sigma Aldrich and used without further purification. The cationic polyelectrolyte, poly(allylamine hydrochloride) (PAH), having a molecular weight of $70 \mathrm{kDa}$ was purchased from Polysciences and was used for mica surface modification. Natural ruby mica sheets obtained from Continental Trade was used as a substrate for the colloidal particle adsorption. The solid pieces of mica were freshly cleaved into thin fragments of desired area and used in each experiment without any pretreatment. Ultrapure water, used throughout this investigation, was obtained using the Milli-Q Elix\&Simplicity 185 purification system from Millipore SA Molsheim, France.

\section{Synthesis of silver nanoparticles}

Silver nanoparticles were obtained by a chemical reduction using trisodium citrate, which has been widely applied for the preparation of various metallic nanoparticles (Kamyshny and Magdassis 2009). An essential advantage of using sodium citrate is that it acts both as a reducing and stabilizing agent. In our work, the reaction was carried out at lower temperature and a shorter period of time than it is commonly applied. This allowed to produce monodisperse suspension of smaller particle than those described in the literature (Lee and Meisel 1981; Pillai and Kamat 2004).

A sample of silver nitrate (200 mg) was dissolved in distilled water to obtain the silver ions concentration of $1.18 \mathrm{mM}$ and then heated rapidly to $88{ }^{\circ} \mathrm{C}$ under stirring (the rate of stirring $300 \mathrm{rpm}$ ). Afterward, $4 \mathrm{ml}$ of $39 \mathrm{mM}$ trisodium citrate solution was added rapidly to the silver solution. The mixture was kept at $88{ }^{\circ} \mathrm{C}$ for 35 min with continuous stirring. After this period of time, the silver sol was immediately cooled to the room temperature. Afterwards, the sol was purified from ionic excess using a stirred membrane filtration cell 
(Millipore, model 8400) with a regenerated cellulose membrane (Millipore, NMWL: $100 \mathrm{kDa}$ ). The washing procedure was repeated until the conductivity of the supernatant solution stabilized at ca. $15-20 \mu \mathrm{S} \mathrm{cm}^{-1}$.

Preparation of silver nanoparticle monolayers

The procedure of preparing silver nanoparticle monolayers on PAH-modified mica was as fallows. First, a saturated PAH monolayer on mica was deposited under diffusion-controlled transport conditions. In order to do this, freshly cleaved mica sheets were placed in the PAH solution, having a concentration of $5 \mathrm{mg} \mathrm{L}^{-1}, I=10^{-2} \mathrm{M} \mathrm{NaCl}$ and $\mathrm{pH}=4$, and left for 15 min. Afterward, mica sheets covered by the polyelectrolyte monolayer were rinsed with water and immersed in the silver suspension.

Deposition of silver nanoparticles was carried out under diffusion-controlled transport from suspensions of different bulk concentrations (10, 25, 50, 100, $\left.150 \mathrm{mg} \mathrm{L}^{-1}\right), \mathrm{pH}=5.9$, and various ionic strengths, varying from $10^{-4}$ to $3 \times 10^{-2} \mathrm{M}$. The deposition time was regulated to obtain silver monolayers of a desired coverage. After deposition, the samples were rinsed with the ultrapure water and air dried. All experiments were performed in a diffusion cells which were equipped with a special glass element that allows for a vertical immersion of mica sheets in the colloidal suspensions. The deposition process was carried out under thermostated conditions, and the temperature was kept constant at $293 \mathrm{~K}$.

Methods of silver particle and monolayer characterization

The weight concentration of the particle suspension was determined by the high precision densitometer: DMA 5000M (Anton Paar). The UV-Vis extinction spectrum was measured using the Shimadzu UV-1800 spectrometer.

The silver particles were characterized by measuring their diffusion coefficient $(D)$ and electrophoretic mobility $\left(\mu_{\mathrm{e}}\right)$ as a function of ionic strength $(I)$ and $\mathrm{pH}$. These parameters were acquired using the Zetasizer Nano ZS from Malvern (measurement range of $3 \mathrm{~nm}-$ $10 \mu \mathrm{m}$ for zeta potential, and $0.6 \mathrm{~nm}-6 \mu \mathrm{m}$ for particle size).

The morphology of silver nanoparticles was investigated using the JEOL JSM-7500F microscope working in transmission mode. Samples for this examination were prepared by dispersing a drop of the silver colloid on a copper grid which was covered by a carbon film. Furthermore, the scanning electron microscope JEOL JSM-7500F was used to determine the coverage of silver monolayers. To insure a sufficient conductivity, the silver nanoparticles samples were covered with a thin layer of chromium.

Independently, the surface concentration of silver particles on the modified mica substrate was quantitatively determined using the atomic force microscopy (AFM). The measurements were carried out using the NT-MDT Solver Pro instrument with the SMENA SFC050L scanning head. Imaging was done in the semicontact mode using silicon probe (polysilicon cantilevers with resonance $120 \mathrm{kHz} \pm 10 \%$, typical tip curvature radius was $10 \mathrm{~nm}$, contact angle $<20^{\circ}$ ).

The zeta potential of bare, polyelectrolyte covered mica and silver monolayers of various coverage was determined via streaming potential measurements using a home-made cell previously described (Zembala and Adamczyk 2000; Zembala et al. 2001). The main part of the cell was a parallel plate channel of dimensions $2 b_{\mathrm{c}} \times 2 c_{\mathrm{c}} \times L=0.027 \times 0.29 \times 6.2 \mathrm{~cm}$, formed by mica sheets separated by a perfluoroethylene spacer. The streaming potential $E_{\mathrm{s}}$ was measured using a pair of $\mathrm{Ag} / \mathrm{AgCl}$ electrodes as a function of the hydrostatic pressure difference $\Delta P$, which was driving the electrolyte flow through the channel. The cell electric conductivity $K_{\mathrm{e}}$ was determined by $\mathrm{Pt}$ electrodes. Knowing the slope of the $E_{\mathrm{s}}$ versus $\Delta P$ dependence, the apparent zeta potential of substrate surface $\left(\zeta_{\mathrm{i}}\right)$ can be calculated from the Smoluchowski relationship

$\zeta_{\mathrm{i}}=\frac{\eta L}{4 \varepsilon b_{\mathrm{c}} c_{\mathrm{c}} R_{\mathrm{e}}}\left(\frac{\Delta E_{\mathrm{s}}}{\Delta P}\right)=\frac{\eta K_{\mathrm{e}}}{\varepsilon}\left(\frac{\Delta E_{\mathrm{s}}}{\Delta P}\right)$

where $\eta$ is the dynamic viscosity of the solution, $\varepsilon$ is the dielectric permittivity, $R_{\mathrm{e}}$ is the electric resistance of the cell governed mainly by the specific conductivity of the electrolyte in the cell.

\section{Results and discussion}

Bulk silver particle characteristics

The concentration of purified silver suspension was determined by a densitometer as described in our previous works (Oćwieja et al. 2011, 2012a, b). The 
sol was first purified using the membrane filtration method, then the specific density of the concentrated sol and its supernatant was measured. The silver sol having the concentration of $550 \mathrm{mg} \mathrm{L}^{-1}$ was then diluted (usually $10-150 \mathrm{mg} \mathrm{L}^{-1}$ ) and used for adsorption experiments.

The silver sol shows a single visible excitation band near $400 \mathrm{~nm}$, attributed to the surface plasmon excitation of silver nanoparticles (Mie 1908), see Fig. 1. The plasmon band is narrow and symmetric, which indicates that the sample does not contain agglomerated particles (Henglein and Giersig 1999; Widoniak et al. 2005). The height of the peak increases monotonically with the sol concentration.

The size distribution and morphology of the silver particles were determined from AFM images and TEM micrographs. The nanoparticle diameter $\left(d_{\mathrm{p}}\right)$ was calculated as the average value from two perpendicular directions and from the surface area of particles, as described before (Oćwieja et al. 2011, 2012a, b). According to the histogram obtained from TEM micrographs, the mean diameter of particles was $28 \mathrm{~nm}$ with a standard deviation of $4 \mathrm{~nm}$.

The average size distribution of particles was also determined by AFM. Silver particles were deposited from a diluted suspension $\left(20 \mathrm{mg} \mathrm{L}^{-1}\right), \mathrm{pH}=5.5$, $I=10^{-2} \mathrm{M}$ for $15 \mathrm{~min}$, on a mica sheet precovered by a supporting PAH layer. The size of the particles was determined using the Nova 1152 software which is coupled directly with AFM microscope. The

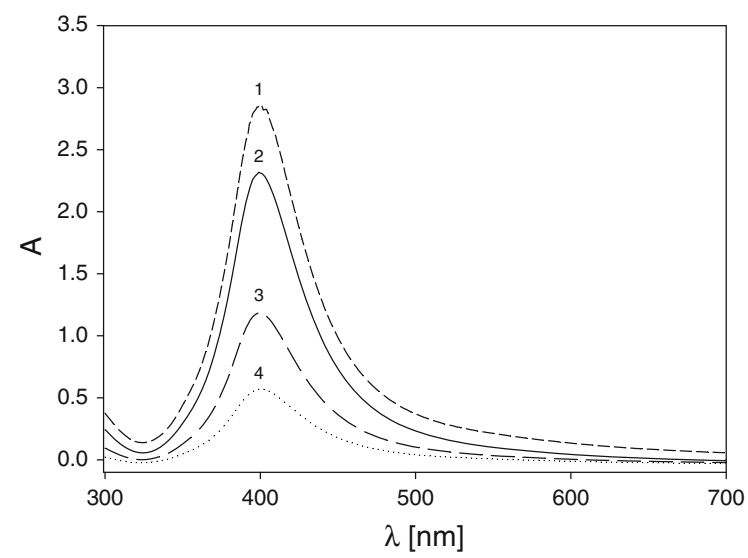

Fig. 1 The UV-Vis absorption spectra of the aqueous silver nanoparticle suspension for various bulk concentrations 1 (dash line) $25 \mathrm{mg} \mathrm{L}^{-1}, 2$ (straight line) $20 \mathrm{mg} \mathrm{L}^{-1}, 3$ (spaced dash line) $10 \mathrm{mg} \mathrm{L}^{-1}, 4$ (dotted line) $5 \mathrm{mg} \mathrm{L}^{-1}$. The peak of the maximum spectrum extinction occurs at $\lambda_{\max }=400 \mathrm{~nm}$ average size of particles determined from the histogram was $29 \mathrm{~nm}$, with a standard deviation of $5 \mathrm{~nm}$.

The average particle size (hydrodynamic diameter, $\left.d_{\mathrm{H}}\right)$ was also determined via diffusion coefficient $(D)$ measurements performed using the dynamic light scattering (DLS) method. Knowing the diffusion coefficient of particles, one can determine the hydrodynamic diameter using the Stokes-Einstein relationship

$d_{H}=\frac{k T}{3 \pi \eta D}$

where $k$ is the Boltzman constant, $T$ is the absolute temperature and $\eta$ is the dynamic viscosity of the solution. The hydrodynamic diameter can be interpreted as the size of an equivalent sphere having the same hydrodynamic resistance coefficient as the particle. The advantage of using this quantity in comparison to the diffusion coefficient, is that it is independent on temperature and liquid viscosity, so it can be used for analyzing the suspension stability under various conditions. For sake of convenience, silver particle size, determined using different techniques are collected in Table 1.

The stability of the silver sol was studied by determining the dependence of the hydrodynamic diameter of particles on ionic strengths varied between $5 \times 10^{-5}$ and $10^{-1} \mathrm{M} \mathrm{NaCl}$ for various $\mathrm{pH}$ (see Fig. 2).

As can be seen, for ionic strengths up to $3 \times 10^{-2} \mathrm{M}$ and $\mathrm{pH}=6.2$, the hydrodynamic diameter was practically constant, attaining an average value of $29 \mathrm{~nm}$ with a standard deviation of $5 \mathrm{~nm}$. The value is in accordance with that previously determined by AFM. A significant increase in the hydrodynamic diameter was observed for ionic strengths higher than $0.05 \mathrm{M}$.

Another important parameter, which describes the electrokinetic charge of particles and the electrostatic interaction among them, is the electrophoretic mobility $\mu_{\mathrm{e}}$, defined as the average translation velocity of colloidal particles under given electric field. The dependence of the electrophoretic mobility of silver nanoparticles on $\mathrm{pH}$ was shown in Fig 3.

The electrophoretic mobility of silver nanoparticles is negative in entire range of ionic strength and $\mathrm{pH}$, indicating that the particles acquired a net negative charge. It increases with ionic strength, from $-3.38 \mu \mathrm{m}$ $\mathrm{cm}(\mathrm{V} \mathrm{s})^{-1}$ for $I=10^{-4} \mathrm{M}$ to $-2.51 \mu \mathrm{m} \mathrm{cm}(\mathrm{V} \mathrm{s})^{-1}$ for $I=10^{-2} \mathrm{M}$ and $\mathrm{pH}=4$. Higher negative charges were observed for lower ionic strengths and higher $\mathrm{pH}$ 
Table 1 Physicochemical characteristics of silver nanoparticles

\begin{tabular}{lll}
\hline Property & Value & Remarks \\
\hline Specific density $\left(\mathrm{g} \mathrm{cm}^{-3}\right)$ & 10.49 & Literature data (Fuertes et al. 2009) \\
Average particle size $(\mathrm{nm})$ & $28 \pm 4$ & From size distribution derived from TEM micrographs \\
Average particle size $(\mathrm{nm})$ & $29 \pm 5$ & From size distribution derived from AFM images \\
Diffusion coefficient $\left(\mathrm{cm}^{2} \mathrm{~s}^{-1}\right)$ & $1.48 \times 10^{-7}$ & Determined by DLS for $T=293 \mathrm{~K}, \mathrm{pH}=6.2 I=5 \times 10^{-2}-0.03 \mathrm{M} \mathrm{NaCl}$ \\
Hydrodynamic diameter $(\mathrm{nm})$ & $29 \pm 5$ & Calculated from Eq. (2) \\
Average particle size $(\mathrm{nm})$ & 28.4 & Calculated from adsorption kinetics Eq. (11) \\
$\begin{array}{l}\text { Geometrical cross-section area } \\
\left(\mathrm{nm}{ }^{2}\right)\end{array}$ & 615 & Calculated from geometry \\
$\begin{array}{l}\text { Plasmon absorption maximum } \\
(\mathrm{nm})\end{array}$ & 400 & Measured for $\mathrm{pH}=6.2 I=10^{-2} \mathrm{M} \mathrm{NaCl}$ and silver sol concentration \\
& & $c_{\mathrm{b}}=5-25 \mathrm{mg} \mathrm{L}-1$
\end{tabular}

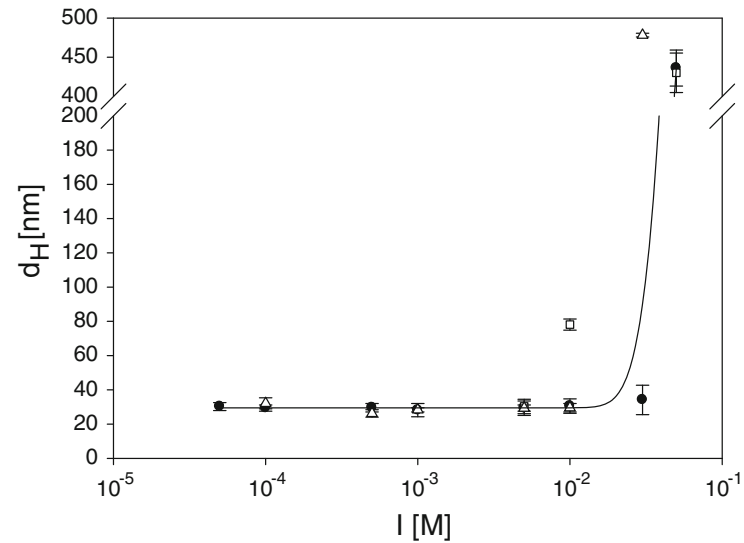

Fig. 2 The dependence of the hydrodynamic diameter of silver nanoparticles on ionic strength, determined by DLS (open square) $\mathrm{pH}=3$, (filled circle) $\mathrm{pH}=6.2$, (open triangle) $\mathrm{pH}=9$, sol concentration $100 \mathrm{mg} \mathrm{L}^{-1}$

values. For $I=10^{-3} \mathrm{M}$ and $\mathrm{pH}=9, \mu_{\mathrm{e}}=-3.48 \mu \mathrm{m}$ $\mathrm{cm}(\mathrm{V} \mathrm{s})^{-1}$, and for $I=10^{-4} \mathrm{M}$ and $\mathrm{pH}=9, \mu_{\mathrm{e}}=$ $-4.08 \mu \mathrm{m} \mathrm{cm}(\mathrm{V} \mathrm{s})^{-1}$.

Knowing the electrophoretic mobility of particles, one can calculate the average number of charges per particle from the Lorentz-Stokes relationship (Dąbkowska and Adamczyk 2012; Wasilewska and Adamczyk 2011)

$N_{\mathrm{c}}=\frac{30 \pi \eta}{1.602} d_{\mathrm{H}} \mu_{\mathrm{e}}$

where $N_{c}$ is expressed as the number of elementary charge $(e)$ per particle $\left(e=1.602 \cdot 10^{-19} \mathrm{C}\right), \eta$ is expressed in $\mathrm{g}(\mathrm{cms})^{-1} d_{\mathrm{H}}$ is the particle diameter expressed in $n m$ and $\mu_{e}$ is expressed in $\mu \mathrm{m} \mathrm{cm}(\mathrm{V} \mathrm{s})^{-1}$.

For pH 6.2 and the ionic strength equal to $10^{-3}$, $10^{-2}$, and $3 \times 10^{-2} \mathrm{M}$, the number of uncompensated

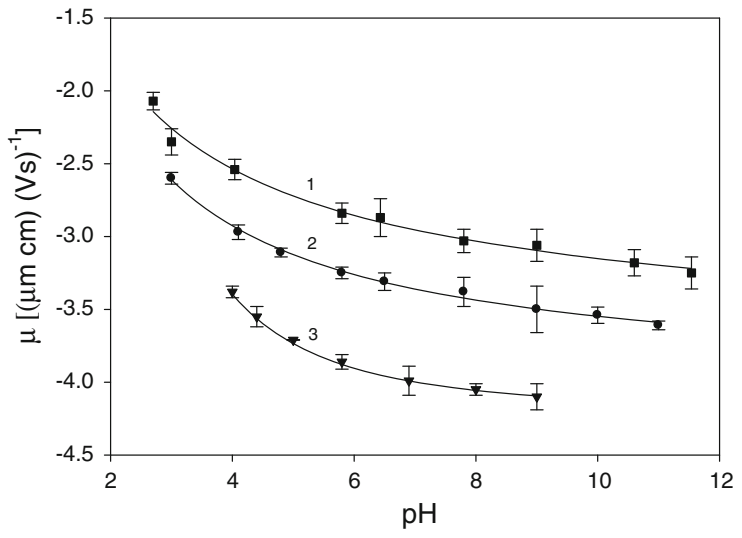

Fig. 3 The dependence of the electrophoretic mobility of silver particles on $\mathrm{pH} 1$ (filled square) $I=10^{-2} \mathrm{M}, 2$ (filled circle) $I=10^{-3} \mathrm{M}, 3$ (filled down-pointing triangle) $I=10^{-4} \mathrm{M}$. The solid lines are a guide to the eye

(electrokinetic) charges was $-54 e,-47 e$, and $-44 e$, respectively.

Knowing the electrophoretic mobility, this quantity can be calculated using Henry's equation

$\zeta_{\mathrm{p}}=\frac{\eta}{\varepsilon f\left(\kappa d_{\mathrm{p}}\right)} \mu_{\mathrm{e}}$

where $\zeta_{p}$ is the zeta potential of particles, $\varepsilon$ is the electric permittivity of the solution, $f\left(\kappa d_{\mathrm{p}}\right)$ is the correction function of the dimensionless parameter, $\kappa d_{\mathrm{p}}, \kappa^{-1}=\left(\frac{\varepsilon k T}{2 e^{2} I}\right)^{1 / 2}$ is the thickness of the electric double layer. For thin double layers $\left(\kappa d_{\mathrm{p}}>10\right), f\left(\kappa d_{\mathrm{p}}\right)$ approaches unity (Smoluchowski's approximation), and for thick double layers $\left(\kappa d_{\mathrm{p}}>1\right), f\left(\kappa d_{\mathrm{p}}\right)$ approaches $3 / 2$ (Hückl approximation). Moreover, in our calculations of the zeta potential, the Ohshima's 
Table 2 The electrophoretic mobility, the number of elementary charge and the zeta potentials of silver nanoparticles for various pH and ionic strength

\begin{tabular}{llllllll}
\hline $\mathrm{pH}$ & $\begin{array}{l}\text { Ionic strength } \\
(\mathrm{M})\end{array}$ & $\kappa d_{\mathrm{p}}$ & $\begin{array}{l}\mu_{\mathrm{e}}, \mu \mathrm{m} \mathrm{cm} \\
(\mathrm{V} \mathrm{s})^{-1}\end{array}$ & $N_{\mathrm{c}}(e)$ & $\begin{array}{l}\zeta_{\mathrm{p}}(\mathrm{mV}) \text { Smoluchowski's } \\
\text { model }\end{array}$ & $\begin{array}{l}\zeta_{\mathrm{p}}(\mathrm{mV}) \text { Henry } \\
\text { model }\end{array}$ & $\begin{array}{l}\zeta_{\mathrm{p}}(\mathrm{mV}) \text { Ohshima's } \\
\text { model }\end{array}$ \\
\hline 3 & 0.001 & 1.45 & -2.60 & -43 & -36.6 & -52.4 & -59.2 \\
& 0.01 & 4.59 & -2.35 & -40 & -33.1 & -43.6 & -48.1 \\
& 0.03 & 7.95 & -2.19 & -36 & -30.8 & -37.9 & -40.3 \\
6.2 & 0.0001 & 0.46 & -3.86 & -64 & -54.4 & -80.5 & -95.1 \\
& 0.001 & 1.45 & -3.25 & -54 & -45.8 & -65.5 & -87.3 \\
& 0.01 & 4.59 & -2.84 & -47 & -40.0 & -52.7 & -62.8 \\
& 0.03 & 7.95 & -2.72 & -44 & -38.3 & -47.1 & -52.3 \\
& 0.0001 & 0.46 & -4.10 & -68 & -57.7 & -85.5 & -105 \\
& 0.001 & 1.45 & -3.50 & -58 & -49.3 & -70.5 & $-*$ \\
& 0.01 & 4.59 & -3.06 & -50 & -43.1 & -56.8 & $-*$ \\
\hline
\end{tabular}

*Oshima model fails

model was used (Ohshima 2006) which includes the relaxation effect of double layer around particles especially for low ionic strengths when the parameter $\kappa d_{\mathrm{p}}$ attains lower values. The zeta potentials of the particles, calculated from three models, are given in the Table 2.

From these measurements one can conclude that the silver particles exhibit a high negative zeta potential for a broad range of $\mathrm{pH}$ and ionic strength, which is expected to promote their efficient deposition on positively charged substrates.

\section{Substrate characteristics}

Except for particle characteristics in the bulk, a proper interpretation of the adsorption phenomena requires a quantitative information about the substrate zeta potential. As mentioned, in our experiments, mica sheets modified by PAH were used as a well-defined substrate. Mica is a chemically stable and molecularly smooth material, characterized by a uniform and homogeneous surface charge distribution. The zeta potential of a bare mica substrate $\left(\zeta_{\mathrm{i}}\right)$ for various ionic strengths and $\mathrm{pH}$, determined using the streaming potential method is shown in Fig. 4. As seen, the zeta potential $\zeta_{\mathrm{i}}$ attained high negative values in the entire range of $\mathrm{pH}$ and ionic strength reaching $-120 \mathrm{mV}$ for $\mathrm{pH}=9$ and $I=10^{-4} \mathrm{M},-62 \mathrm{mV}$ for $\mathrm{pH}=5.5$ and $I=10^{-2} \mathrm{M}$, and $-37 \mathrm{mV}$ for $\mathrm{pH}=3.5$ and $I=3 \times 10^{-2} \mathrm{M}$.

To promote an efficient particle deposition, the negative zeta potential of mica was converted to positive by controlled adsorption of PAH molecules, which is a popular and useful method of surface functionalization (Lowack and Helm 1995; Oćwieja et al. 2011; Schmitt et al. 1999). The quantitative analysis of PAH monolayer formation on the mica substrate was investigated using the streaming potential method, according to the procedure described in our previous works (Adamczyk et al. 2006; Oćwieja et al. 2011). The amount of the adsorbed polyelectrolyte was regulated by changing its bulk concentration and adsorption times. The dependence of the apparent zeta potential on PAH coverage at ionic strength $I=10^{-2} \mathrm{M}$ is shown in Fig. 5 .

The coverage of PAH monolayers was regulated by changing the bulk concentration of polyelectrolyte solutions (1-10 $\mathrm{mg} \mathrm{L}^{-1}$ ) and the adsorption time (5$30 \mathrm{~min}$ ). As seen, the zeta potential of mica increases abruptly with the coverage of PAH. The most significant change is observed for low coverage up to 0.1 , when the slope of $\zeta$ versus $\Theta$ dependence exceeds 10. For higher coverage of PAH, $\Theta>0.25$, the zeta potential variations become rather minor. Thus, for $\Theta>0.3$ limiting zeta potentials of PAH are attained. As proved in our previous works (Adamczyk et al. 2006), for dense monolayers formed, the asymptotic values of the zeta potential approach 1/ $\sqrt{ } 2=0.71$ of the bulk zeta potential of the particles or polyelectrolyte molecules. The experimental results shown in Fig. 5, were interpreted in terms of the electrokinetic model in which adsorbed molecules are treated as isolated entities exhibiting a 3D charge 


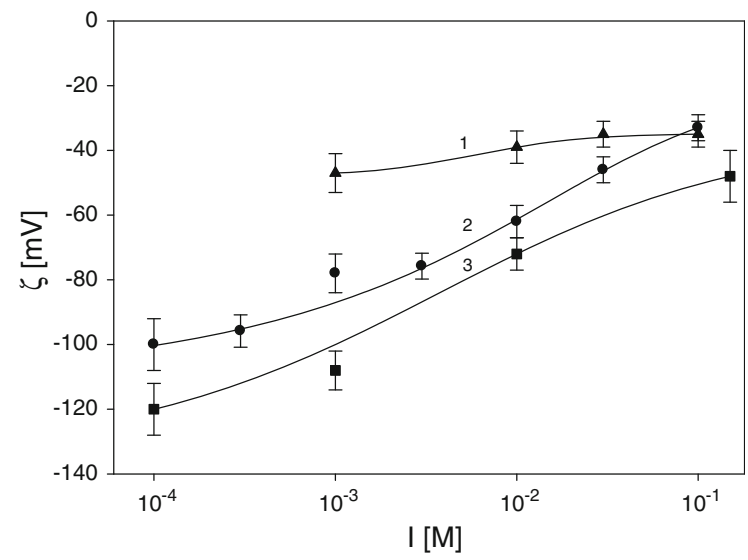

Fig. 4 The dependence of the apparent zeta potential of mica on ionic strength 1 (filled triangle) $\mathrm{pH}=3.5,2$ (filled circle) $\mathrm{pH}=5.5,3$ (filled square) $\mathrm{pH}=9.0$ determined by the streaming potential method. The solids lines are a guide to the eye

distribution (Adamczyk et al. 2010; Adamczyk et al. 2011; Morga et al. 2012).

Using this approach, the expression for the streaming potential of an interface covered by particles can be formulated in the analytical form

$\zeta(\Theta)=F_{\mathrm{i}}(\Theta) \zeta_{\mathrm{i}}+F_{\mathrm{p}}(\Theta) \zeta_{\mathrm{p}}$

where $\zeta(\Theta)$ is the zeta potential of the particle covered substrate and $F_{\mathrm{i}}(\Theta), F_{\mathrm{p}}(\Theta)$ are the dimensionless functions of the particle coverage and the $\kappa d_{p}$ parameter.

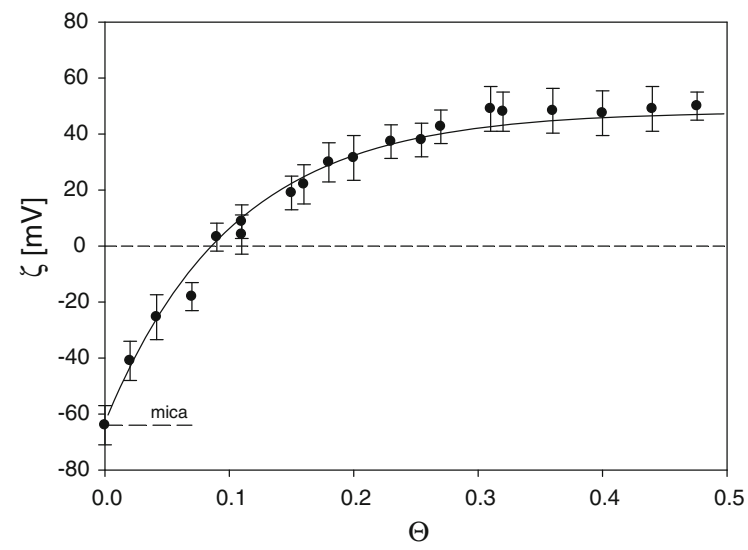

Fig. 5 The dependence of the zeta potential of mica $\zeta$ on the coverage of PAH $\Theta$, (filled circle $)\left(I=10^{-2} \mathrm{M}, \mathrm{pH}=5.5\right)$ determined by the streaming potential method. The solid line denotes the theoretical results calculated from the electrokinetic model, Eqs. (5), (6)
The $F_{\mathrm{i}}(\Theta)$ function reflects the effect of the flow damping in the vicinity of deposited particles, which diminishes the rate of ion transport (convective current) and the $F_{\mathrm{p}}(\Theta)$ function describes the convective current from the electric double layer at particles (Adamczyk et al. 2010).

It should be mentioned that Eq. (5) does not involve any fitting parameters because the functions $F_{\mathrm{i}}(\Theta), F_{\mathrm{p}}(\Theta)$ were theoretically determined.

Theoretical results were also reported in the previous work (Adamczyk et al. 2010), which allowed one to determine the $F_{\mathrm{i}}(\Theta), F_{\mathrm{p}}(\Theta)$ functions for the entire range of coverage in the limit of thin double layers. These results were obtained by numerically evaluating the flow field in the vicinity of adsorbed particles using the multipole expansion method. The exact numerical results can be approximated by the following analytical interpolation functions, with a margin of error $( \pm) 1 \%$

$F_{\mathrm{i}}(\Theta)=\mathrm{e}^{-C_{\mathrm{i}}^{0} \theta}$

$F_{\mathrm{p}}(\Theta)=\frac{1}{\sqrt{2}}\left(1-\mathrm{e}^{-\sqrt{2} C_{\mathrm{p}}^{0} \theta}\right)$

where the $C_{\mathrm{i}}, C_{\mathrm{p}}$ are the functions of $\kappa a$ parameter, attaining constant values of $C_{\mathrm{i}}^{0}=10.2$ and $C_{\mathrm{p}}^{0}=6.51$, for $\kappa a>1$.

Obviously, for bare surfaces, where $\Theta=0$, $F_{\mathrm{i}}(\Theta)=1$ and $F_{\mathrm{p}}(\Theta)=0$. On the other hand, for high coverage range the $F_{\mathrm{i}}(\Theta)$ function vanishes and $F_{\mathrm{p}}(\Theta)$ tends to $\frac{1}{\sqrt{2}}$. Thus, using Eq. (5) one can deduce that the limiting zeta potential for surfaces covered by particles is given by

$\zeta_{\infty}=\zeta_{\mathrm{p}} / \sqrt{2}=0.701 \zeta_{\mathrm{p}}$

Theoretical results calculated using Eqs. (5), (6) are plotted in Fig. 5 as a solid line. As can be seen, they properly reflect the experimental data for the entire coverage range. In particular, the validity of Eq. (7) for describing PAH monolayer behavior was confirmed.

The dependence of this limiting value of the zeta potential of PAH monolayer is plotted in Fig. 6. As can be seen, it attains the value of $49 \mathrm{mV}$ for $I=10^{-2} \mathrm{M}$ and $60 \mathrm{mV}$ for $I=10^{-4} \mathrm{M}$. Such high positive values of the zeta potential suggest that an efficient deposition of negatively charged particles should take place. This was confirmed by particle deposition experiments discussed in the next section. 
Kinetics of silver particle deposition

Deposition of silver particles on PAH-modified mica was conducted under diffusion-controlled transport according to the procedure described above. The first step in these kinetic measurements was the deposition of a saturated PAH monolayer on mica sheets. Afterward, the particle deposition was carried out using silver sols of the concentration ranging from 5 to $150 \mathrm{mg} \mathrm{L}^{-1}$, for a desired time period ranging from 5 to $1500 \mathrm{~min}$. The surface concentration of the deposited particles $N_{\mathrm{s}}$ was determined by direct enumeration, using AFM images and SEM micrographs. Usually, 8-10 various areas were considered with the overall number of particles counted about 1,000, which ensured the precision of these measurements better than $3 \%$. The results were expressed as the surface concentration of particles $N_{\mathrm{s}}$, defined as the number of particles per unit area of the substrate. For the sake of convenience, this area was assumed to be one square $\mu \mathrm{m}$; thus $N_{\mathrm{s}}$ has the dimension of $\mu \mathrm{m}^{-2}$. Knowing the average number of silver particles per unit area, the size of the particle and the surface area $\Delta S$, the surface concentration can be converted to dimensionless coverage defined as:

$\Theta=\frac{\pi d_{\mathrm{p}}^{2} N_{\mathrm{s}}}{4}$

Knowing $N_{\mathrm{s}}$ as a function of deposition time, particle adsorption kinetics for various experimental conditions can be determined. However, it should be

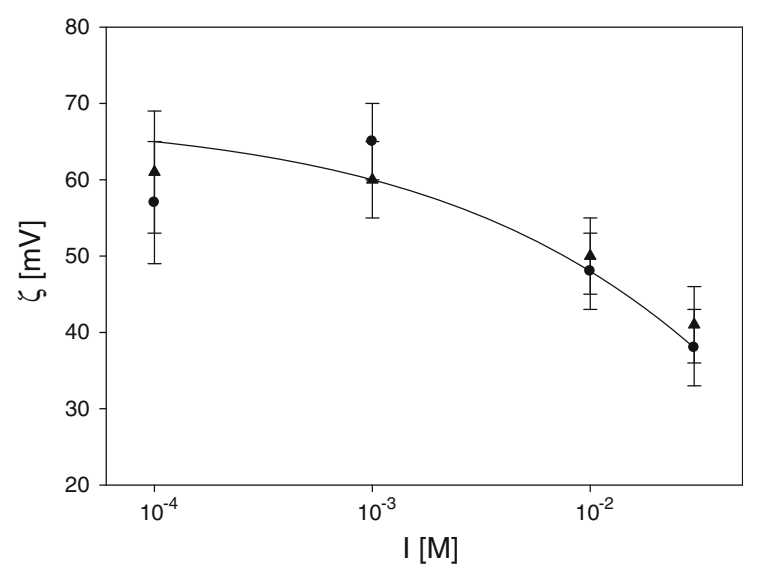

Fig. 6 The dependence of the zeta potential of saturated PAH monolayers on ionic strength determined by the streaming potential method (filled triangle) $\mathrm{pH}=3.5$ (filled circle) $\mathrm{pH}=5.5$. The solid line is a guide to the eye mentioned that for the diffusion-controlled transport, it is appropriate to express the kinetic runs in terms of the square root of deposition time $t^{1 / 2}$, rather than the primary time variable $t$. For a low coverage range, where the surface blocking effects remain negligible, the kinetics of particle adsorption is described by the theoretical formula (Adamczyk 2006)

$N_{S}=2\left(\frac{D}{\pi}\right)^{1 / 2} t^{1 / 2} n_{b}$

where $D$ is the diffusion coefficient and $n_{\mathrm{b}}$ is the bulk number concentration of particles connected with the weight concentration $c_{\mathrm{p}}$ (expressed in $\mathrm{mg} \mathrm{L}^{-1}$ ) via the linear dependence

$n_{b}=\frac{6 \times 10^{-6}}{\pi d_{p}^{3} \rho_{p}} c_{p}$

where $\rho_{\mathrm{p}}$ is the specific density of silver (see Table 1).

Typical kinetic runs obtained for a wide range of bulk silver particle concentration, $10-150 \mathrm{mg} \mathrm{L}^{-1}$ and deposition conditions $I=10^{-2} \mathrm{M} \mathrm{NaCl}, \mathrm{pH}=5.5$, and $T=293 \mathrm{~K}$ are shown in Fig. 7a. As can be seen, for $t^{1 / 2}<10 \mathrm{~min}^{1 / 2}$ (adsorption time $t<100 \mathrm{~min}$ ) particle deposition was linear in this coordinate system, with the slope increasing proportionally to the bulk concentration.

This indicates that the dependence of $N_{\mathrm{s}} / c_{b}$ on $t^{1 / 2}$ should yield a universal straight-line dependence as can be observed in Fig. 7b. The linear dependence of $N_{\mathrm{s}} / c_{\mathrm{b}}$ $\left(\mathrm{mg} \mathrm{L}^{-1} \mu \mathrm{m}^{-2}\right)$ on $t^{1 / 2}\left(\min ^{1 / 2}\right)$ exhibits the slope $s_{\mathrm{D}}=$ $\Delta\left(\frac{N_{\mathrm{s}}}{c_{\mathrm{b}}}\right) / \Delta t^{1 / 2}$ of $0.271 \mathrm{mg} \quad \mathrm{L}^{-1} \mu \mathrm{m}^{-2} \min ^{-1 / 2}=$ $3.49 \times 10^{12} \mathrm{~cm} \mathrm{~g}^{-1} \mathrm{~s}^{-1 / 2}$. This confirms the proportionality of the particle adsorption rate to the bulk suspension concentration, in accordance with Eq. (9). Knowing the slope, one can experimentally determine the diameter of silver particles from the dependence previously derived (Oćwieja et al. 2012a, b):

$d_{\mathrm{m}}=\left(\frac{12}{\rho_{\mathrm{p}} \pi^{2} s_{\mathrm{D}}}\right)^{2 / 7}\left(\frac{k T}{3 \eta}\right)^{1 / 7}$

In our case, using the above value of $s_{\mathrm{D}}$ and noting that $T=293 \mathrm{~K}, \quad \eta=0.01 \mathrm{~g}(\mathrm{~cm} \mathrm{~s})^{-1}$ and $\rho_{\mathrm{p}}=$ $10.49 \mathrm{~g} \mathrm{~cm}^{-3}$, one obtains $d_{\mathrm{m}}=28.4 \mathrm{~nm}$ from Eq. (11). As can be seen, the value of the "diffusion" diameter of particles determined from the adsorption kinetic experiments agrees with the values determined 
using dynamic light scattering or spectroscopic measurements (TEM, AFM), see Table 1.

In the next series of experiments, the kinetics of particle deposition for various ionic strengths was investigated for longer times with the aim of determining the maximum coverage of self-assembled monolayers. Particle monolayers formed under ionic strength $10^{-2} \mathrm{M}$, and $\mathrm{pH}=5.5$ for increasing deposition times are shown in Fig. 8.

In Fig. 9, kinetic runs obtained for various ionic strengths are shown. The surface concentration of particles was determined by both AFM (full points) and SEM (hollow points). Characteristic features of these kinetic runs are a linear increase in $N_{s}$ with $t^{1 / 2}$
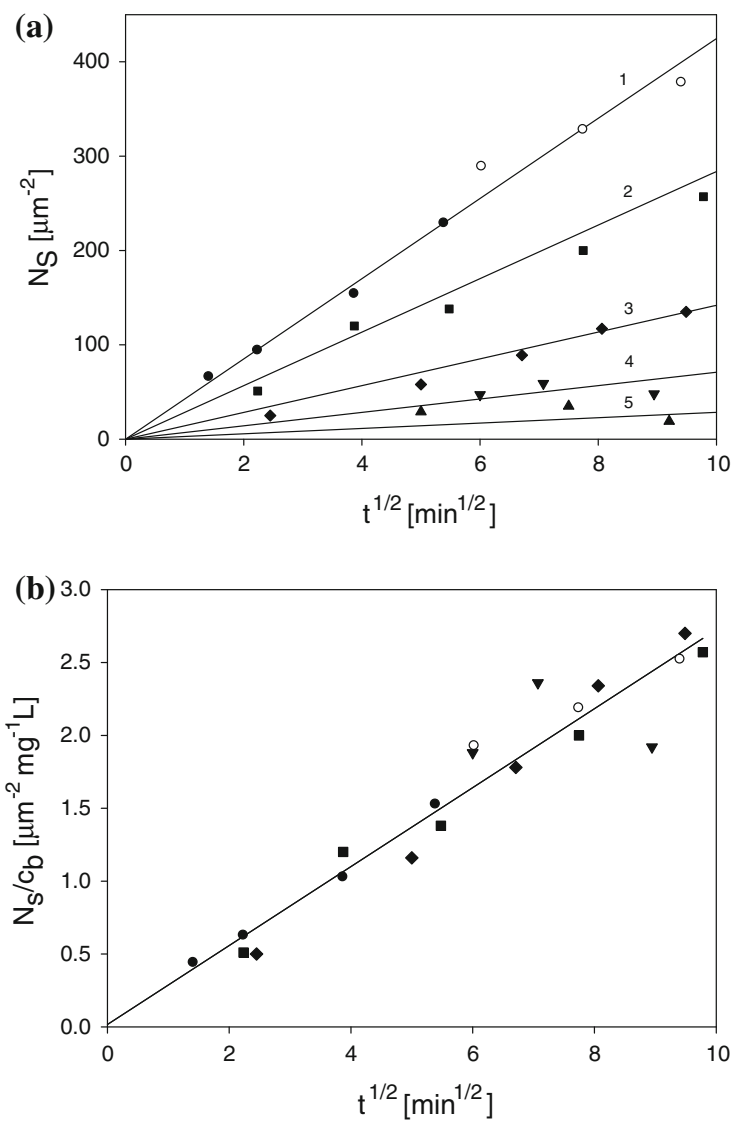

Fig. 7 a The kinetics of silver particle adsorption on mica determined for various bulk suspension concentrations 1 (filled circle, open circle) $150 \mathrm{mg} \mathrm{L}^{-1}, 2$ (filled square) $100 \mathrm{mg} \mathrm{L}^{-1}, 3$ (filled diamond) $50 \mathrm{mg} \mathrm{L}^{-1}, 4$ (filled down-pointing triangle) $25 \mathrm{mg} \mathrm{L}^{-1}$, and 5 (filled triangle) $10 \mathrm{mg} \mathrm{L}^{-1}$. b The dependence of the reduced surface concentration $N_{\mathrm{s}} / c_{\mathrm{b}}\left(\mu \mathrm{m}^{-2} \mathrm{mg} \mathrm{L}^{-1}\right)$ on the square root of adsorption time $t^{1 / 2}\left(\min ^{1 / 2}\right)$ for shorter times and then, after reaching some critical time, an abrupt stabilization of the surface concentration at a constant value. This behavior was quantitatively described in terms of the random sequential adsorption (RSA) model depicted by the solid lines in Fig. 9. This model was applied before for describing irreversible adsorption (deposition) of colloid microparticles (polystyrene latexes) (Adamczyk and Szyk 2000; Kleimann et al. 2006), nanoparticles (Oćwieja et al. 2012a, b; Pericet-Camora et al. 2004; Popa et al. 2007) and proteins (Dąbkowska and Adamczyk 2012). The RSA model is also extensively discussed in the book (Adamczyk 2006).

In Fig. 9, the maximum particle coverage $\Theta_{\mathrm{mx}}$ systematically increases with ionic strength from 0.07 for $I=10^{-4} \mathrm{M}$ to 0.33 for $I=10^{-2} \mathrm{M}$. It is worth mentioning, that for higher ionic strengths the silver suspension became unstable and the aggregation process was observed (see Fig. 2), therefore the adsorption cannot be studied for $I>10^{-2} \mathrm{M}$.

Streaming potential of silver monolayer on PAHmodified mica

The disadvantage of the AFM and SEM methods is that they are working under ex situ conditions, which require drying of particle monolayers. This is eliminated in the streaming potential method, allowing for in situ measurements. The measurements were carried out according to the following procedure: in the first step, the streaming potential cell, assembled from two freshly cleaved mica sheets forming the channel, was filled in with the PAH solution $\left(c_{\mathrm{PAH}}=5 \mathrm{mg} \mathrm{L}^{-1}\right.$, $\left.I=10^{-2} \mathrm{M} \mathrm{NaCl}\right)$. The PAH molecules were allowed to adsorb for a required time under diffusion-controlled transport forming a saturated monolayer. After the deposition was completed the cell was flushed with a pure electrolyte solution to remove weakly bonded particles and the streaming potential measurement was conducted in situ. The zeta potential of the mica covered by particles was calculated using the equation (Eq. 1). Knowing the zeta potential, one can control the coverage of PAH (see Fig. 5). Afterward, working still under in situ conditions, the procedure was repeated for the silver particles. To obtain a desired coverage, the amount of adsorbed particles was regulated by changing its bulk concentration (50-200 $\mathrm{mg} \mathrm{L}^{-1}$ ) and keeping the desired adsorption time (1-40 min). The zeta potential of PAH-covered 
(a)

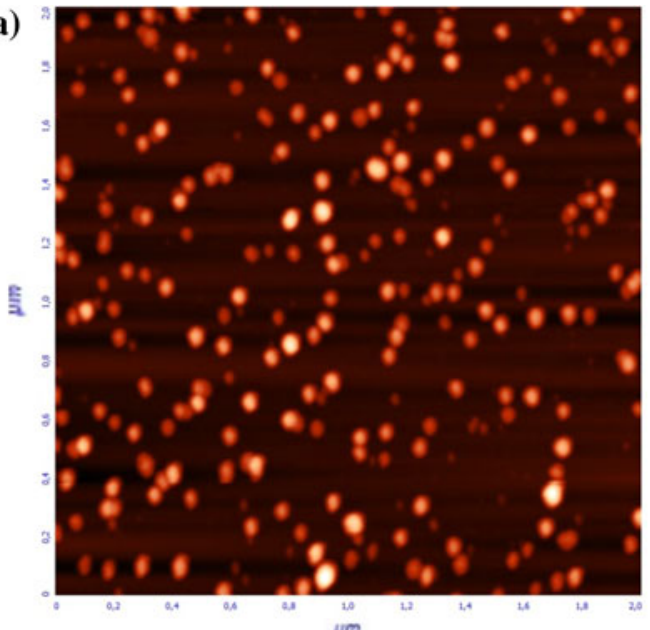

(b)

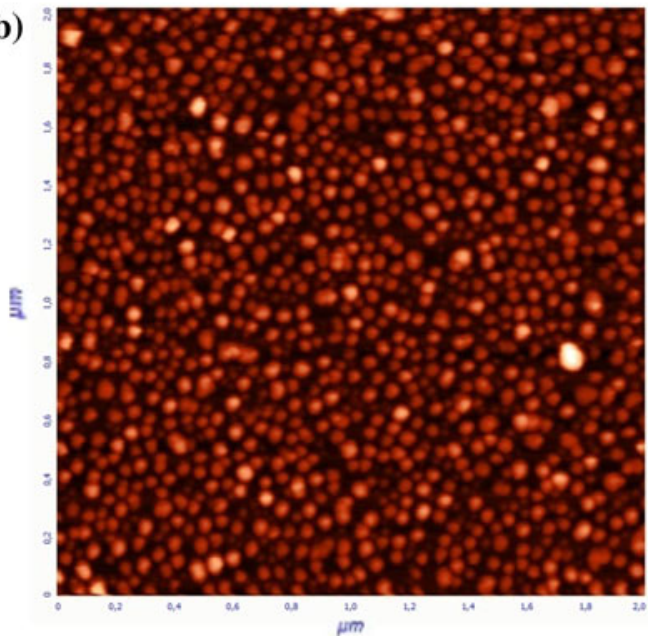

Fig. 8 AFM images and SEM micrographs of silver particle monolayers adsorbed on mica modified by the saturated PAH monolayer. Particle deposition conditions $c_{\mathrm{p}}=150 \mathrm{mg} \mathrm{L}^{-1}$,

mica on the coverage of silver particles obtained for $I=10^{-2} \mathrm{M}$ is shown in Fig. 10 .

As seen, the formation of particle monolayer results in an abrupt decrease in the surface zeta potential with the slope $\zeta$ versus $\Theta$ considerably exceeding 10 for $\Theta$ close to 0.1 . The inversion in sign of polyelectrolyte monolayer is observed for $\Theta_{p}=0.1$. For higher coverage of silver particles $(\Theta>0.2)$, the zeta potential variations become rather minor and for

$\Theta_{\mathrm{p}}>0.25$ the zeta potential of the silver layer attains the asymptotic value of $-25 \mathrm{mV}$. Thus, it was confirmed that the limiting zeta potential $\zeta$ obtained for maximum coverage of silver nanoparticles is systematically lower than its bulk value equal to
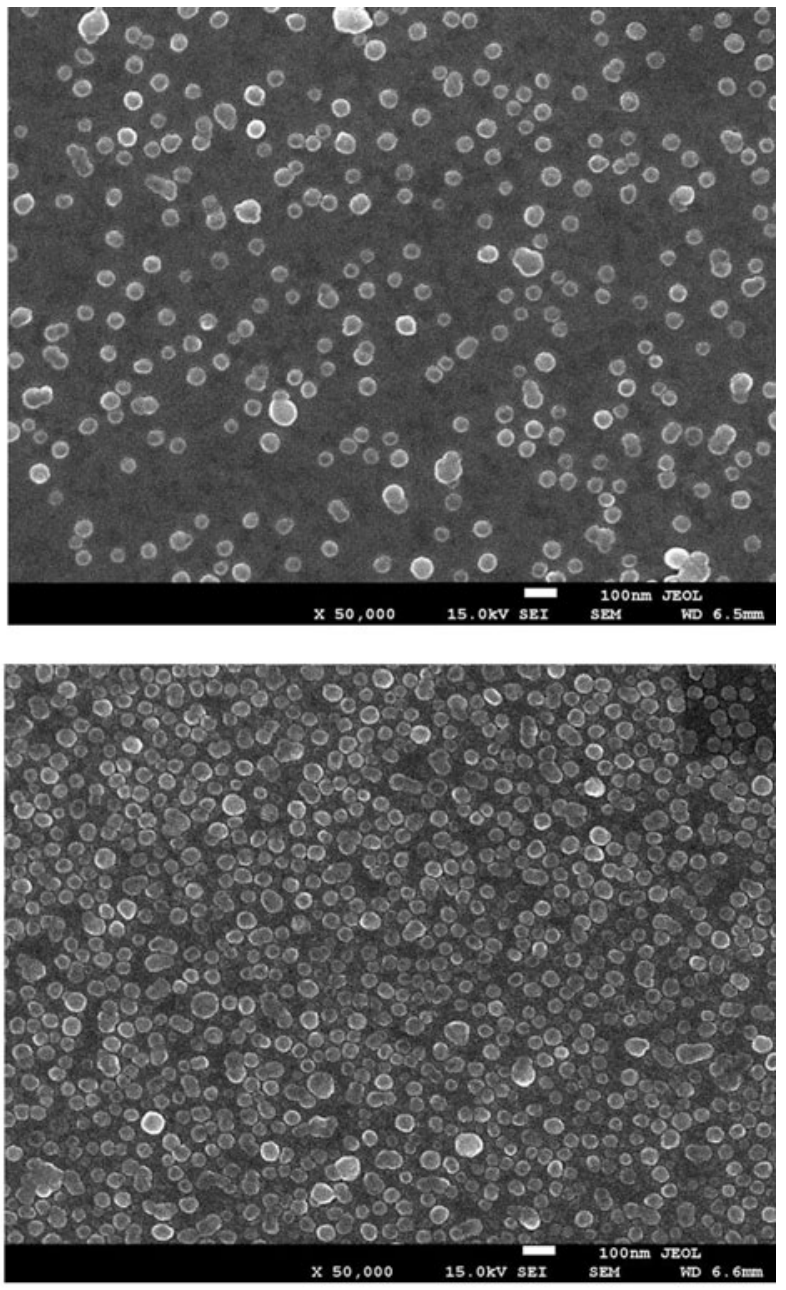

$\mathrm{pH}=5.5, \quad I=10^{-2} \mathrm{M}, \quad$ a deposition time $t=2 \mathrm{~min}$, $N_{\mathrm{s}}=54 \mu_{\mathrm{m}}^{-2}, \Theta=0.03, \quad \mathbf{b}$ deposition time $t=40 \mathrm{~min}$, $N_{\mathrm{s}}=276 \mu \mathrm{m}^{-2}, \Theta=0.17$

$-39 \mathrm{mV}$. As proved in our previous works (Adamczyk et al. 2006; Zaucha et al. 2011), for dense particle monolayers, the asymptotic values of the zeta potential approaches $1 / \sqrt{ } 2=0.701$ of the bulk zeta potential of the nanoparticles. This was interpreted theoretically in terms of the electrokinetic model described above (Eq. 6). As seen in Fig. 10, the theoretical results obtained from Eqs. (5), (6), properly reflect the experimental data for the entire coverage range. To the best of our knowledge, this is the first result of this kind reported for conducting particles.

Furthermore, Eqs. (5) and (6) can be transformed to a useful, universal form by introducing the normalized zeta potential (Dąbkowska and Adamczyk 2012) 


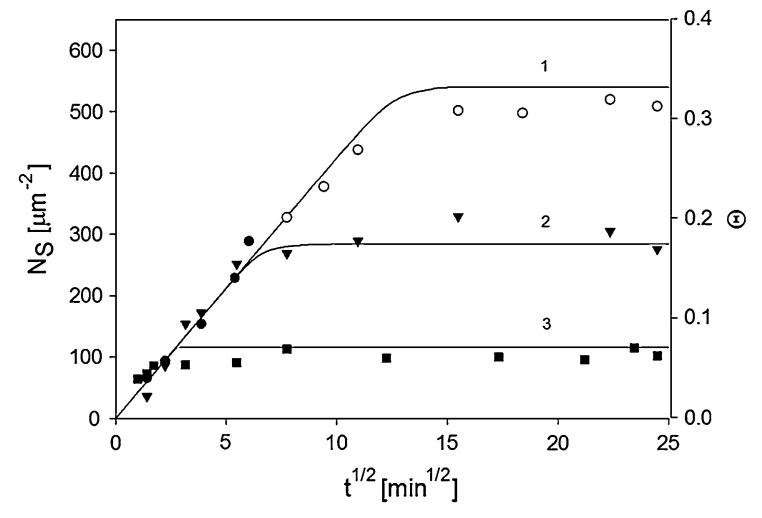

Fig. 9 The kinetics of silver particle adsorption on mica determined for various ionic strengths 1 (filled circle, open circle) $10^{-2} \mathrm{M}, 2$ (filled down-pointing triangle) $10^{-3} \mathrm{M}, 3$ (filled square) $10^{-4} \mathrm{M}$ determined using AFM (full points) and SEM (hollow points). Particle deposition conditions $\mathrm{pH}=5.5$, $T=293 \mathrm{~K}, c_{\mathrm{b}}=150 \mathrm{mg} \mathrm{L}^{-1}$. The solid lines denote the theoretical results calculated from the RSA model

$\bar{\zeta}=\frac{\zeta-\zeta_{p} / \sqrt{2}}{\zeta_{i}-\zeta_{p} / \sqrt{2}}=\frac{\zeta-\zeta_{\infty}}{\zeta_{i}-\zeta_{\infty}}$

Using this transformation, one can express the results obtained for various conditions (various ionic strength) through the relationship

$\bar{\zeta}=e_{i}{ }^{-C_{i} \Theta_{S}}$

It should be mentioned that Eq. (13) is universally valid for an arbitrary particle size, zeta potential of particles and substrates, $\mathrm{pH}$, etc. In practice, the unknown coverage of the silver monolayer on an

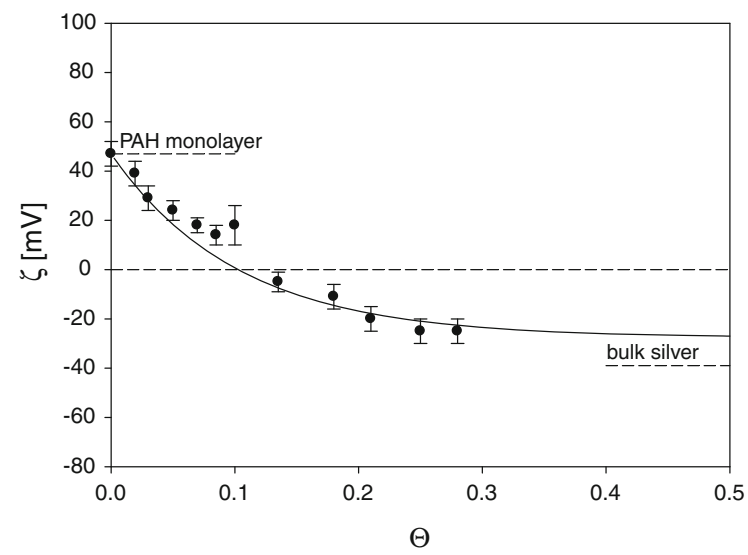

Fig. 10 The dependence of the zeta potential of PAH monolayer $\zeta$ on the coverage of silver particles $\Theta$ determined by the streaming potential method. The deposition conditions $I=10^{-2} \mathrm{M} \mathrm{NaCl}, \mathrm{pH}=5.8$ arbitrary substrate can be determined via the streaming potential measurements from the following relationship obtained by inverting Eq. (13)

$\Theta_{\mathrm{S}}=-\frac{1}{C_{\mathrm{i}}} \ln \frac{\zeta-\zeta_{\infty}}{\zeta_{\mathrm{i}}-\zeta_{\infty}}$

Obviously, in order to apply Eq. (14), one should also know the zeta potential of the uncovered substrate $\zeta_{\mathrm{i}}$ and the zeta potential of particles in the bulk $\zeta_{\mathrm{p}}$. The results calculated this way are compared in Fig. 11 with results obtained from direct AFM and SEM determination of particle coverage $\Theta_{\mathrm{M}}$.

As seen in Fig. 11, the results obtained from streaming potential studies, $\Theta_{\mathrm{s}}$, are in a good agreement with those obtained from the microscope images $\Theta_{\mathrm{M}}$. This is reflected by the slope of the regression being exactly one. This is of importance because these result prove that the streaming potential method is a useful tool not only for determining the zeta potential of particles but also for precisely calculating the coverage directly under wet, in situ conditions.

In addition, the streaming potential measurements create a unique possibility of thorough characterization of nanoparticle monolayers, for example, to determine the isoelectric point (Morga et al. 2012) or monolayer stability under various physicochemical conditions within a prolonged time period.

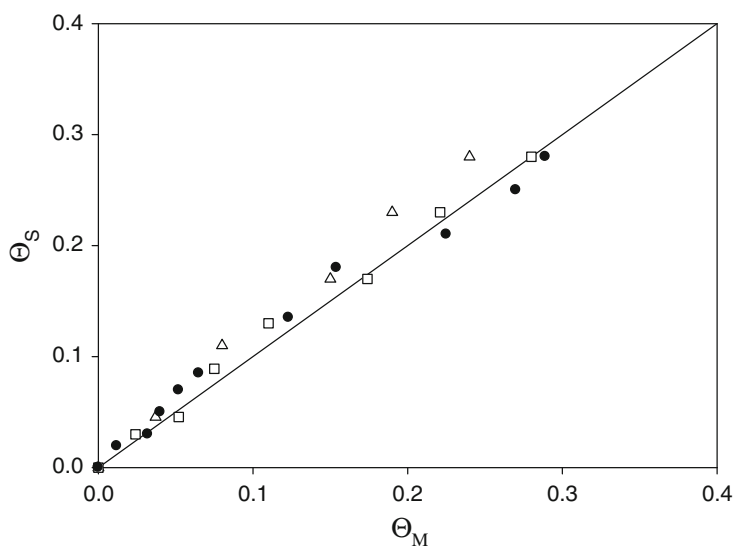

Fig. 11 The universal plot dependence of the coverage of silver particles, calculated on the basis of the streaming potential measurements $\Theta_{\mathrm{S}}$ from Eq. (13), on the coverage $\Theta_{\mathrm{M}}$, obtained from the microscope images. The points denote experimental results obtained for various ionic strengths of the $\mathrm{NaCl}$ electrolyte $I$ (open triangle) $I=10^{-4} \mathrm{M}$, (open square) $I=10^{-3} \mathrm{M},($ filled circle $) I=10^{-2} \mathrm{M}$ 


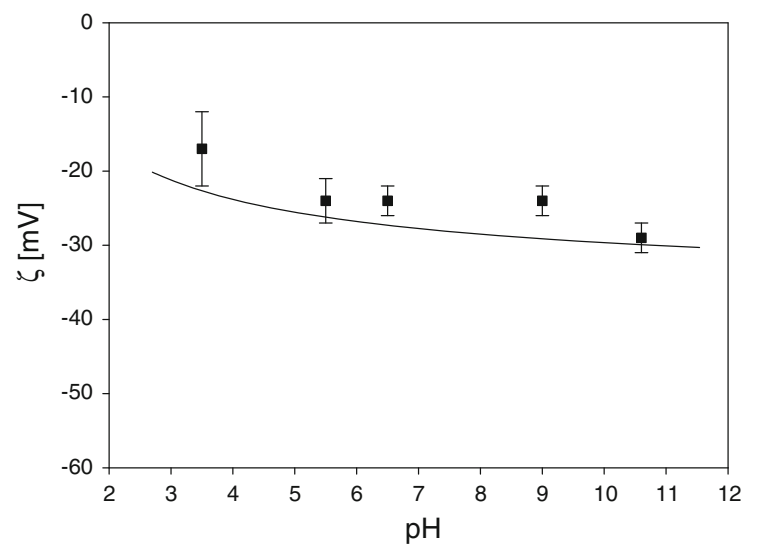

Fig. 12 The dependence of the zeta potential determined by the streaming potential and electrophoretic measurements on $\mathrm{pH}$ $\left(I=10^{-2} \mathrm{M}\right)$. Square points (filled square) represent the streaming potential results obtained from $\mathrm{pH}$-cycle measurements. The solid line denotes the reference data obtained in the bulk (smoothened), i.e., $\zeta_{\infty}=\zeta_{\mathrm{p}} / \sqrt{2}$. The measurements were performed for the dense silver particle monolayer deposited at $\mathrm{pH}=5.8$ and $I=10^{-2} \mathrm{M}$

In Fig. 12 the dependence of the silver particle monolayer zeta potential on $\mathrm{pH}$ is shown.

The experimental procedure was as follows: first the silver monolayer having the coverage of 0.28 was obtained. Afterward, $\mathrm{pH}$ was changed in a discrete manner from $\mathrm{pH}=3.5$ to $\mathrm{pH}=10.5$. The streaming potential pertinent to a fixed $\mathrm{pH}$ value was simultaneously measured. The monolayer zeta potential was calculated from Eq. (1). A few $\mathrm{pH}$ cycles were performed, which showed that the zeta potential at each $\mathrm{pH}$ was constant within experimental error bounds. These results were compared with the reference values calculated from Eq. (7) using the bulk zeta potential of the silver particle. This is also depicted in Fig. 12 as a solid line. As can be noticed, the agreement of the 'bulk' and 'surface' values of the silver particle zeta potential is quite satisfactory for the entire range of $\mathrm{pH}$ (within standard deviation).

\section{Conclusions}

Using a stable suspension of silver nanoparticles, homogeneous monolayers were produced in the selfassembly process, carried out under diffusion transport. The monolayer coverage, determined via AFM and SEM imaging, can be precisely regulated by the suspension concentration, adsorption time, and the ionic strength.
It was demonstrated that the coverage of the monolayers can be more efficiently determined via the in situ streaming potential measurements. The variations of the calculated zeta potential of the monolayers with the particle coverage were adequately interpreted in terms of the electrokinetic model expressed by Eqs. (5) and (6). This is of significance for basic science because the validity of the electrokinetic model to interpret the behavior of the conductive nanoparticle systems was confirmed for the first time.

Using this model, one can directly determine, via the experimental streaming potential data, the kinetics of particle adsorption and desorption under various transport conditions such as diffusion and forced convection (flow). In addition, using the electrokinetic studies, the characteristics of the monolayers can be acquired, in particular, one can determine their stability against $\mathrm{pH}$ cycling and ionic strength variations. This has a practical significance for optimizing conditions of stable silver nanoparticle film preparation on solid substrates.

\section{Highlights}

- Silver particle monolayers of controlled density and structure were produced.

- The properties of monolayers were thoroughly characterized via in situ streaming potential measurements.

- A convenient method of determining coverage of silver nanoparticle films was developed.

Acknowledgments This work was financially supported by the Research Grant: POIG 01.01.02-12-028/09-00. The authors are grateful to dr Elżbieta Bielańska for performing SEM analyses.

Open Access This article is distributed under the terms of the Creative Commons Attribution License which permits any use, distribution, and reproduction in any medium, provided the original author(s) and the source are credited.

\section{References}

Adamczyk Z (2006) Interface science and technology: particles at interfaces: interactions, deposition, structure. Elsevier, Amsterdam

Adamczyk Z, Szyk L (2000) Kinetics of irreversible adsorption of latex particles under diffusion-controlled transport. Langmuir 16:5730-5737 
Adamczyk Z, Zembala M, Michna A (2006) Polyelectrolyte adsorption layers studied by streaming potential and particle deposition. J Colloid Interface Sci 303:353-364

Adamczyk Z, Sadlej K, Wajnryb E, Nattich M, Ekiel-Jeżewska ML, Bławzdziewicz J (2010) Streaming potential studies of colloid, polyelectrolyte and protein deposition. Adv Colloid Interface Sci 153:1-29

Adamczyk Z, Nattich M, Wasilewska M, Zaucha M (2011) Colloid particle and protein deposition-electrokinetic studies. Adv Colloid Interface Sci 168:3-28

Arbab M (2001) The base layer effect on the d.c. conductivity and structure of direct current magnetron sputtered thin films of silver. Thin Solid Films 381:15-21

Aslan K, Lakowicz JR, Geddes CD (2005) Rapid deposition of triangular silver nanoplates on planar surface; application to metal-enhanced fluorescence. J Phys Chem B 109:62476251

Bandyopadhyay K, Patil V, Vijayamohanan K, Sastry M (1997) Adsorption of silver colloidal particles through covalent linkage to self-assembled monolayers. Langmuir 13: 5244-5248

Bar G, Rubin S, Cutts RW, Taylor TN, Zawodzinski TA (1996) Dendrimer-modified silicon oxide surfacesas platforms for the deposition of gold and silver colloid monolayers: preparation method, characterization, and correlation between microstructure and optical properties. Langmuir 12:1172-1179

Brouwer EAM, Kooij ES, Wormeester H, Poelsema B (2003) Ionic strength dependent kinetics of nanocolloidal gold deposition. Langmuir 19:8102-8108

Dąbkowska M, Adamczyk Z (2012) Ionic strength effect in HSA adsorption on mica determined by streaming potential measurements. J Colloid Interface Sci 366:105-113

Estrada-Raygoza IC, Sotelo-Lerma M, Ramirez-Bon R (2006) Structural and morphological characterization of chemically deposited silver films. J Phys Chem Solids 67:782-788

Fuertes MC, Marchena M, Marchi MC, Wolosiuk A, Soler-Illia GJ (2009) Controlled deposition of silver nanoparticles in mesoporous single-or multilayer thin films: from tuned pore filling to selective spatial location of nanometric objects. Small 5:272-280

Green M, Liu FM (2003) SERS substrates fabricated by Island Lithography: the silver/pyridine system. J Phys Chem B 107:13015-13021

Henglein A, Giersig M (1999) Formation of colloidal silver nanoparticles: capping action of citrate. J Phys Chem B 103:9533-9539

Inoue M, Hayashi Y, Takizawa H, Suganuma K (2010) Formation mechanism of nanostructured $\mathrm{Ag}$ films from $\mathrm{Ag}_{2} \mathrm{O}$ particles using a sonoprocess. Colloid Polym Sci 288:1061-1069

Jiang ZJ, Liu ChY, Sun LW (2005) Catalytic properties of silver nanoparticles supported on silica spheres. J Phys Chem B 109:1730-1735

Kachan S, Stenzel O, Ponyavina A (2006) High-absorbing gradient multilayer coatings with silver nanoparticles. Appl Phys B 84:281-287

Kaczor A, Małek K, Barańska M (2010) Pyridine on colloidal silver. Polarization of surface studies by surface-enhanced Raman scattering and density functional theory methods. J Phys Chem C 114:3909-3917
Kamyshny A, Magdassi S (2009) Aqueous dispersion of metallic nanoparticles. In: Starov VM (ed) Nanoscience colloidal and interfacial, 1st edn. CRC Press, New York, pp 747-778

Kim JS, Kuk E, Yu KN, Kim JH, Park SJ, Lee HJ, Kim SH, Park YK, Park YH, Hwang CY, Kim YK, Lee Y, Jeong DH, Cho MH (2007) Antimicrobial effects of silver nanoparticles. Nanomedicine 3:95-101

Kim K, Park HB, Shin KS (2008) Easy deposition of Ag onto polystyrene beads for developing surface enhanced Raman scattering based molecular sensors. J Colloid Interface Sci 318:195-201

Kleimann J, Lecoultre G, Papastavrou G, Jeanneret S, Galletto P, Koper GJM, Borkovec M (2006) Deposition of nanosized latex particles onto silica and cellulose surfaces studied by optical reflectometery. J Colloid Interface Sci 303:460-471

Lee PC, Meisel DJ (1981) Catalysis of the hydrogen evolution reaction by colloidal $\mathrm{Ag}$ anchored in perfluorosulfonate resin. J Catal 70:160-167

Lee YH, Dai S, Young JP (1997) Silver-doped sol-gel films as the substrate for surface-enhanced Raman scattering. J Raman Spectrosc 28:635-639

Lee HJ, Yeo SY, Jeong SH (2003) Antibacterial effect of nanosized silver colloidal solution on textile fibers. J Mater Sci 38:2199-2204

Li Y, Wu Y, Ong BS (2005) Facile synthesis of silver nanoparticles useful for fabrication of high-conductivity elements for printed electronics. J Am Chem Soc 127: 3266-3267

Lowack K, Helm CA (1995) Molecular mechanisms controlling the self-assembly process of polyelectrolyte multilayers. Macromolecules 28:2912-2921

Magdassis S, Bassa A, Vinetsky Y, Kamyshny A (2003) Silver nanoparticles as pigments for water-based ink-jet inks. J Chem Mater 15:2208-2217

Mie G (1908) Beitrage zur Optik truber Medien, speziell kolloidaler Metallosungen. Ann Phys 25:377-445

Mittler S (2010) Imaging of thin films, and its application in the life sciences. In: Kumar CSSR (ed) Nanostructured thin films and surfaces, 1st edn. Wiley-VCH, Weinheim, p 366

Morga M, Adamczyk Z, Oćwieja M (2012) Hematite nanoparticle monolayers on mica electrokinetic characteristics. J Colloid Interface Sci 386:121-128

Oćwieja M, Adamczyk Z, Morga M, Michna A (2011) High density silver nanoparticle monolayers produced by colloid self-assembly on polyelectrolyte supporting layers. JColloid Interface Sci 364:39-48

Oćwieja M, Adamczyk Z, Kubiak K (2012a) Tuning properties of silver particle monolayers via controlled adsorptiondesorption processes. J Colloid Interface Sci 376:1-11

Oćwieja M, Adamczyk Z, Morga M, Bielańska E, Węgrzynowicz A (2012b) Hematite nanoparticle monolayers on mica preparation by controlled self-assembly. J Colloid Interface Sci 386:51-59

Ohshima H (2006) Interface science and technology: theory of colloid and interfacial electric phenomena. Elsevier, Amsterdam

Pericet-Camora R, Papastavrou G, Borkovec M (2004) Atomic force microscopy study of the adsorption and electrostatic 
self-organization of poly(amidoamine) dendrimers on mica. Langmuir 20:3264-3270

Pillai ZS, Kamat PV (2004) What factors control the size and shape of silver in the citrate ion reduction method? J Phys Chem B 108:945-951

Popa I, Cahill BP, Maroni P, Papastavrou G, Borkovec M (2007) Thin adsorbed films of a strong cationic polyelectrolyte on silica substrates. J Colloid Interface Sci 309:28-35

Reiter G, Bubeck C, Stamm M (1992) Formation of silver islands on Langmuir-Blodgett films as investigated by X-ray reflectometry. Langmuir 8:1881-1884

Schmitt J, Mächtle P, Eck D, Möhwald H, Helm CA (1999) Preparation and optical properties of colloidal gold monolayers. Langmuir 15:3256-3266

Wasilewska M, Adamczyk Z (2011) Fibrinogen adsorption on mica studied by AFM and in situ streaming potential measurements. Langmuir 27:689-696

Widoniak J, Eiden-Assmann S, Maret G (2005) Silver particles tailoring of shapes and sizes. Colloids Surf A Physicochem Eng Asp 270-271:340-344
Yan Y, Kang SZ, Mu J (2007) Preparation of high quality Ag film from Ag nanoparticles. Appl Surf Sci 253:4677-4679

Yang Y, Shi J, Tanaka T, Nogami M (2007) Self-assembled silver nanochains for surface-enhanced Raman scattering. Langmuir 23:12042-12047

Yougen H, Tao Z, Pengli Z, Rong S (2012) Preparation of monodisperse polystyrene/silver composite microspheres and their catalytic properties. Colloid Polym Sci 290:401-409

Yuan Z, Dryden NH, Vittal JJ, Puddephatt RJ (1995) Chemical vapor deposition of silver. Chem Mater 7:1696-1702

Zaucha M, Adamczyk Z, Barbasz J (2011) Zeta potential of particle bilayers on mica: a streaming potential study. J Colloid Interface Sci 360:195-203

Zembala M, Adamczyk Z (2000) Measurments of streaming potential for mica covered by colloid particles. Langmuir 16:1593-1601

Zembala M, Adamczyk Z, Warszyński P (2001) Influence of adsorbed particles on streaming potential of mica. Colloids Surf A Physicochem Eng Asp 195:3-15 